\title{
INFORMATION EXCHANGE IN ONCOLOGY OUTPATIENT CLINICS: SOURCE, VALENCE AND UNCERTAINTY
}

\author{
MARGARET ROGERS ${ }^{\mathrm{a}, *}$ and CHRIS TODD ${ }^{\mathrm{b}}$ \\ ${ }^{\mathrm{a}}$ General Practice and Primary Care Research Unit, Institute of Public Health, University of Cambridge, \\ Robinson Way, Cambridge CB2 2SR, UK \\ ${ }^{\mathrm{b}}$ School of Nursing, Midwifery and Health Visiting, University of Manchester, Coupland III Building, Oxford Road, \\ Manchester M13 9PL, UK
}

\begin{abstract}
SUMMARY
A large literature of doctor-patient communication exists, yet little is known about how symptom information is communicated in cancer care. This qualitative study explores the exchange of symptom and clinical information between cancer patients and oncologists in outpatient clinics of a regional teaching hospital. Verbatim transcripts of consultations between 14 doctors and 43 post-treatment follow-up patients from eight consultants' clinics were subjected to analytic induction and microinteractional analysis techniques. Findings from these analyses indicate that information about patients was accorded varying relevance by doctors depending upon its source, valence and certainty. Doctors' requests for information was contingent upon certainty of clinical information. Symptom information was elicited from patients only when clinical information with high certainty was unavailable. If negative patient information was volunteered, it was not addressed when positive clinical information was present and cancer treatment was not indicated. It appears that information in outpatient oncology consultations is organised according to a hierarchy and is used to make treatment decisions and not primarily for symptom management. Copyright (C) 2002 John Wiley \& Sons, Ltd.
\end{abstract}

\section{INTRODUCTION}

Despite advances in cancer management over recent decades, there are numerous reports of poorly controlled symptoms in both hospital and primary care settings (Cleeland et al., 1994; Dunlop, 1989; Larue et al., 1995; Sykes et al., 1992; Whelan et al., 1997). For example, over twothirds of cancer patients studied in large, multicentred surveys reported pain and up to half of these do not receive adequate pain management (Cleeland et al., 1994; Larue et al., 1995). Furthermore, poor agreement between professional and patient assessments of symptoms and distress is commonly found across cancer care

\footnotetext{
*Correspondence to: General Practice and Primary Care Research Unit, Institute of Public Health, University of Cambridge, Robinson Way, Cambridge CB2 2SR, UK. Tel.: + 1223-330524; fax: + 1223-762515;

e-mail: msr1002@medschl.cam.ac.uk
}

settings and professional groups (Au et al., 1994; Ford et al., 1994; Maguire et al., 1999; Newell et al., 1998; Slevin et al., 1988) with professionals underestimating the presence and severity of up to $87 \%$ of symptoms (Grande et al., 1997; Higginson and McCarthy, 1993; Passik et al., 1998; Stephens et al., 1997). Concordance between professionals' and patients' perceptions about symptoms tends to be greatest where there is an absence of symptoms or where they are mild (Brunelli et al., 1998; Malone et al., 1993; Passik et al., 1998; Stephens et al., 1997). However, agreement in assessment of symptoms decreases with increasing severity, with a marked tendency to underestimate the level of severity (Passik et al., 1998; Stephens et al., 1997).

Thus, inadequately controlled symptoms in cancer patients are at least partly due to professionals underestimating their presence and severity (Chan and Woodruff, 1997; Cleary and Carbone, 1997). Several factors are likely to be culpable here. Patients assess the severity of their symptoms 
based upon their own experiences. Doctors' assessments are based on their wider clinical experiences and they may therefore have specific expectations concerning patients' conditions (Stephens et al., 1997). It is therefore plausible that professionals report values related to patients' symptoms according to their expectations rather than the individual patient's state (Brunelli et al., 1998; Heaven and Maguire, 1997). The problems of poorly identified symptoms and their suboptimal management in cancer patients are clearly related. In turn, they are associated with communication between patients and doctors responsible for their care.

A substantial literature related to doctorpatient interactions in primary care exists (Byrne and Long, 1984; Roter and Hall, 1992; Stewart and Roter, 1989; Stimson and Webb, 1975; Tuckett et al., 1985). Findings from these studies have imparted insight into doctor-patient communication and useful guidelines for general practice. However, these findings are not necessarily applicable to doctor-patient interactions in oncology as they potentially differ in essential ways. Oncology consultations may be depicted as more specialised, serious, complex and frightening (Butow et al., 1995). Structural differences also exist. For example, patients visit their general practitioners (GPs) at their local surgeries in an environment that is probably familiar. In contrast, interactions with oncologists take place on unfamiliar territory as hospital patients either in an inpatient ward or in an outpatient department. Moreover, discussions about cancer-related problems with cancer specialists are conceivably more threatening than those held with GPs.

Communication between doctors and cancer patients has been extensively researched (Northouse and Northouse, 1987). The majority of these publications can be classified as: (a) information disclosure by doctors and 'bad news' consultations (Maguire et al., 1999); (b) patient preference for and satisfaction with information provided by doctors; (c) patient involvement in medical decision-making; and (d) communication skills for doctors. Guidelines for 'breaking bad news' and for 'good communication' have been derived primarily from expert opinion (Butow et al., 1995). Furthermore, most of the published studies utilised interviews or surveys to obtain patient and clinician attitudes of these issues. Consequently, these types of publications do not provide insight into the actual communication process between doctors and cancer patients as they interact with one another.

A search of the English language literature using BIDS, Medline and follow-up of cited references revealed 16 papers reporting observed interactions between cancer patients and oncologists (Blanchard et al., 1983, 1986, 1988, 1990; Borgers et al., 1993; Brown et al., 1999; Butow et al., 1995; Ford et al., 1996; Glaser and Strauss, 1965; Labrecque et al., 1991; Lutfey and Maynard, 1998; McIntosh, 1977; Quint, 1965; Sher et al., 1997; Siminoff et al., 1989; Street and Voigt, 1997). Most of these studies used some type of checklist to record doctors' and/or patients' communication and most followed these observations with questionnaires to obtain patient-clinician attitudes about these issues. Three seminal papers (Glaser and Strauss, 1965; McIntosh, 1977; Quint, 1965) report the process of doctors communicating information related to diagnosis and prognosis to hospitalised cancer patients, whereby information about cancer is actively concealed from patients. More recently, Lutfey and Maynard (1998) through a detailed, turn-by-turn analysis of verbatim transcripts, found that whilst the oncologist did not attempt to conceal the prognosis, the 'bad news' was delivered in a cautious way without using the word 'dying'.

Despite the plethora of literature on doctorpatient communication, little is known about how cancer patients' problems and concerns are communicated during outpatient oncology treatment. The aim of this qualitative study is to explore the exchange of symptom and clinical information between cancer patients and oncologists.

\section{METHODS}

\section{Recruitment}

Participants were recruited from the oncology outpatients department of a regional teaching hospital. A sample of adult cancer patients, representative of eight participating consultant oncologists' clinics, was identified by randomly selecting clinic sessions and then approaching consecutive patients on the clinic list for informed consent. The researcher (M.R.) introduced herself to patients on their arrival at the Oncology Centre, 
verbally explained the study, gave written information sheets and obtained written informed consent before patients moved to the treatment area where observations were made. Patients therefore had opportunity to withdraw their consent prior to seeing their doctors. Ninety-six per cent of patients approached consented. The study was described to medical and nursing staff as well as patients and their companions as an observational study of communication. No particular focus to the study was emphasised.

\section{Data collection}

The researcher sat in to observe and inconspicuously audio record 74 consultations with different patients: seven having their initial oncology consultations; 24 consulting for active treatment; and 43 having post-treatment follow-up consultations. Observations of behaviour and pertinent details were recorded in contemporaneous field notes. The researcher was present during physical examinations as well, and transcripts contain these discussions too. Field notes were used to aid interpretation of the transcribed audiotapes by providing context for each consultation, such as the location of the interaction, patient demographic and medical details.

\section{The sample}

Whilst one might argue that initial consultations with new patients or those during active treatment may need to be more medically orientated, it is during follow-up visits that one would expect patients to be given the most opportunity to talk about their physical problems and psycho-social and emotional concerns. Hence, in this paper we focus on 43 post-treatment follow-up consultations.

Twenty-five female and 18 male follow-up patients, aged $25-83 \mathrm{yr} \quad($ mean $=53 \mathrm{yr} ;$ S.D. $=$ $16 \mathrm{yr}$ ) were observed. The most common cancers were leukaemia (7), gynaecological (7), breast (6), testicular (4) and lymphomas (4). Companions were present during 23/43 consultations. Five of these patients had been previously treated with a curative intent; the remaining had received at least first-line treatment. Of the 14 clinicians consulted, eight were consultants, two senior registrars, two registrars and two clinical assistants. Consultants
Table 1. Grade, gender and number of consultations of doctors in follow up sample

\begin{tabular}{lllll}
\hline Grade & $\begin{array}{l}\text { Number of } \\
\text { consultations }\end{array}$ & \multicolumn{2}{l}{ Gender } & Total \\
\cline { 3 - 4 } & & Male & Female & \\
\hline Consultant & 28 & 7 & 1 & 8 \\
Senior registrar & 9 & 1 & 1 & 2 \\
Registrar & 4 & 1 & 1 & 2 \\
Clinical assistant & 2 & 0 & 2 & 2 \\
Total & 43 & 9 & 5 & 14 \\
\hline
\end{tabular}

saw nearly two-thirds (28/43) of patients, whilst the clinical assistants ${ }^{\dagger}$ saw only one patient each (Table 1). Nurses were present during some part of $34 / 43$ consultations and primarily performed administrative tasks.

\section{Data analysis}

The audio recordings of the consultations were transcribed verbatim. From these data, a modified analytic inductive technique (Bloor, 1976, 1978a; Silverman, 1993) was used to build a model, which categorised patient and doctor information regarding symptoms and clinical data. Further examination of clinicians' talk, using microinteractional analysis (Frankel, 1984) revealed how information was provided to patients and how doctors responded to patient information, which we report with our findings. This analysis is theoretically grounded and is guided by conversational analysis of institutional talk (Drew and Heritage, 1992; Heritage, 1997). We used this model inductively to explore the exchange of symptom and clinical information within consultations and to explain how patients' symptoms are managed during their oncology outpatient visits.

Categories used in this model are defined as follows:

(i) Source: Information exchanged during consultations was categorised as (1) patient information or (2) clinical information. Patient information was provided by patients or companions and was elicited by such questions from doctors

\footnotetext{
${ }^{\dagger}$ In the UK, clinical assistants are doctors who are not consultants and occupy non-training posts.
} 
as, 'Are you having any problems like pain?' or volunteered spontaneously such as when patients report 'feeling a little bit low'. Patient information was further categorised as (1) being observable by others such as sweating, 'lumps and bumps' and vomiting or (2) perceivable only by themselves such as pain, feelings of nausea or fatigue.

Information provided by doctors was categorised as clinical information. This information was derived from investigations such as scans, X-rays and blood tests; from examining patients; or from clinical observations such as tumour measurements.

(ii) Valence: Patient information was classified as 'positive' if patients expressed beneficial changes in their status, that is they said that previously experienced symptoms had been resolved or they denied anything was causing problems when asked by doctors. Patient information was considered 'negative' if patients or their companions reported troublesome symptoms. Clinical information was classified as 'positive' if parameters fell within acceptable ranges and 'negative' when abnormalities were noted.

(iii) Certainty of clinical information: Certainty of clinical information was classified dependent upon the individual parameter and particular cancer involved. Clinical information was categorised as having high certainty when its presence was sufficient to initiate treatment. For example, tumour markers monitored by blood tests are used in the treatment of several cancers. Whereas an elevated tumour marker found in testicular cancer is sufficient evidence to initiate treatment and hence has high clinical certainty, an elevated tumour marker in ovarian cancer is incomplete evidence and hence, has low clinical certainty. Inter-rater reliability between the author-coders of the categorisation process was tested using the kappa statistic (Siegel and Castellan, 1988). Interrater reliability was good for both valence and certainty $(\kappa=0.814$ and $=0.839$, respectively).

Our $2 \times 2 \times 2$ model sub-divides information according to source, valence and certainty (Figure 1). For example, a consultation with a patient who has been treated for testicular cancer who feels well and whose doctor reports that his tumour marker is normal would be located in the anterior upper left corner of the model because both patient and clinical information are positive and the clinical information has high certainty. In contrast, a consultation with a patient who has been treated for thyroid cancer who feels well but

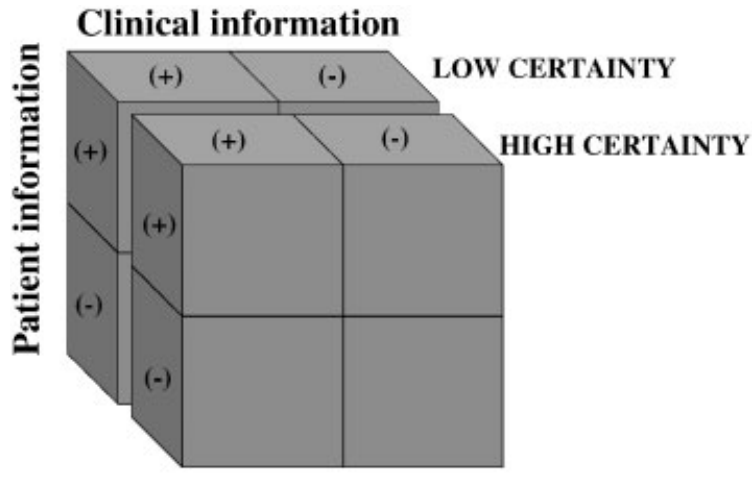

Figure 1. Model of communication.

Table 2. Cell 1: $(+)$ patient and $(+)$ clinical information

\begin{tabular}{ll}
\hline High certainty & Low certainty \\
\hline 8 consultations & 2 consultations \\
7 'How are you's?' & 'Nothing to report?' \\
'lumps and bumps'; fever & 'Want to mention anything?' \\
No treatment & No treatment \\
\hline
\end{tabular}

who has an elevated thyroglobulin level would be placed in the posterior upper right corner of the model, as the patient information is positive but the clinical information is negative and has low certainty.

\section{RESULTS}

The following findings are derived from the application of the three-dimensional model to the 43 post-treatment follow-up consultations which ranged in length from 2 to $25 \mathrm{~min}$ (mean $=9 \mathrm{~min}$; S.D. $=5 \mathrm{~min})$. For clarity, we report the findings on a cell-by-cell basis.

Cell 1: Consultations with both positive patient and clinical information (Table 2). There were 10 consultations, eight of which had evidence of clinical information with high certainty available to the doctor at the beginning of the consultation. In 7/8 consultations, doctors asked patients, 'How are you?' Patients appeared to respond to this as a greeting (Sacks, 1975) with for example, 'Fine, thank you' and doctors did not subsequently reformulate the question into 
a clinical assessment. Unlike consultations where clinical information with high certainty was unavailable, these doctors did not ask about potential problems such as difficulty in swallowing, bowel problems or pain. The only exception was a patient with lymphoma who was asked about observable clinical signs-'Any new lumps or bumps anywhere?'

Two consultations had clinical information with low certainty available. Beyond 'How are you?', patients were asked very generally if they were experiencing difficulties, for example, 'Nothing to report?' No cancer treatment was offered to these 10 patients.

Cell 2: Consultations with positive patient information but negative clinical information (Table 3). There were five such consultations; two contained high certainty negative clinical information. In one consultation with high certainty, a patient who had previously chosen to defer further treatment was advised to start chemotherapy even though he felt well. His doctor's questions about 'lumps and bumps' could be construed as an attempt to involve him in deciding upon the need for treatment (Maynard, 1992). In the other consultation with high certainty, no attempt at eliciting patient information beyond 'How are you?' was observed and the negative clinical information was formulated as 'not much change in the situation'.

In the three consultations with negative low certainty clinical information, doctors asked about specific potential problems. All patients replied negatively and none were offered treatment. However, one patient was advised to have further investigations even though she had no complaints. She responded, 'Well I think you're taking an awful lot of trouble over someone what feels particularly well'. In the remaining two, oncologists formulated the decision to wait until the patients became symptomatic before offering treatment-'Whilst you are very well at the moment, it doesn't make sense to give you treatment just for that... [the elevated ovarian tumour marker]'.

Cell 3: Consultations with negative patient information but positive clinical information (Table 4). There were 14 such consultations, eight of which contained clinical information with high certainty. For these eight, the only elicitations were in the form of 'How are you?' When patients volunteered information about symptoms, doctors briefly acknowledged their complaints. In $3 / 8$ with high certainty, doctors indicated negative patient information was unimportant-'There isn't anything really to worry about'. In another, the oncologist interrupted the patient's report of pain with a contradictory observation-'That's good. You seem to be looking pretty good'. In $4 / 8$ consultations, patients' complaints were disregarded, for example, by oncologists introducing the positive clinical information or asking unrelated questions.

Whilst specific patient information such as pain, eating, walking and sleeping difficulties was elicited in the six consultations where clinical information had low certainty but was positive, evoked patients' complaints were not fully explored as doctors changed the focus by concentrating on the physical examination or asking unrelated questions:

Pt: ... I'm just not sleeping at all well really.

Dr: Hot flushes?

Pt: No, no. That's fine because I'm on the the/

Dr: /The HRT, yes. Which one are you on?

One of six patients was asked a series of questions about his severe headaches, but the oncologist decided that the negative patient information was not due to cancer and the topic was not pursued further-'I mean it is unlikely that it has anything to do with this [motioning to the patient's stomach]'. In only one consultation with low certainty information derived from the
Table 3. Cell 2: $(+)$ patient and $(-)$ clinical information

\begin{tabular}{ll}
\hline High certainty & Low certainty \\
\hline 2 consultations & 3 consultations \\
1 'How are you?' & Symptoms elicited \\
1 'lumps and bumps' & 1 investigation \\
1 'no change' & No treatment \\
1 treatment & \\
\hline
\end{tabular}

Table 4. Cell $3(-)$ patient and $(+)$ clinical information

\begin{tabular}{ll}
\hline High certainty & Low certainty \\
\hline 8 consultations & 6 consultations \\
'How are you's?' only & Symptoms elicited \\
No treatment & 1 investigation \\
& No treatment \\
\hline
\end{tabular}


Table 5. Cell 4: (-) patient and (-) clinical information

\begin{tabular}{ll}
\hline High certainty & Low certainty \\
\hline 3 consultations & 11 consultations \\
1 'How are you?' & Symptoms elicited \\
2 location of pain elicited & 5 investigation \\
3 treatment & 1 treatment \\
\hline
\end{tabular}

physical examination, did the patient's negative elicited information warrant attention-'We'll send you for a chest X-ray to make sure the problem is still under control'. No treatment was offered to any patients.

Cell 4: Consultations with both negative patient information and clinical information (Table 5). Fourteen consultations were located here, three had evidence of high certainty clinical information. One of the three patients was asked, 'How are you?' This patient and one other were questioned only about the location of their pain. These three patients were offered cancer treatment.

In 6/11 consultations where clinical information had low certainty, and where patients volunteered information about pain and bleeding in addition to doctors' questions, further investigations were advised for five patients and one was offered treatment. In another four consultations, doctors reformulated both negative patient and clinical information as 'no change' and therefore not requiring treatment. In two of these, the patients were very passive; however, one was offered an analgesic prescription. In a third, the patient had previously refused treatment and portrayed herself as an expert in the management of her symptoms-'Yes, the pain relief I'm on at the moment seems to be working ... If I'm in a bit more pain, I just top up with the Sevredol'. Over the course of the fourth consultation, the patient raised a series of discomforts and worries, which the doctor indicated were not significant.

In the final consultation with low certainty, negative clinical information was deemed to be not due to cancer. Here the doctor sought to establish the cause of anaemia. Although the patient reported problems with pain, this did not appear to interest the doctor. These problems were not addressed as the doctor continued with his checklist of questions.

\section{DISCUSSION}

The benefits of good doctor-patient communication are manifold. It helps to ensure that most symptoms are elicited (Fallowfield, 1992) thereby producing a better assessment upon which to judge whether treatment has been effective and to make further management decisions. Also, communication affects both physical and emotional outcomes for patients (Stewart, 1995). Our study examines in part, the process of communication between cancer patients and their doctors and points to evidence which appears to indicate that not only are symptoms not elicited but that many of those which do arise during consultations are not addressed.

The major findings of this paper are three-fold: (a) information about patients was accorded varying relevance by doctors depending upon its source, valence and certainty; (b) doctors' communication with patients followed patterns influenced by certainty of clinical information; (c) and the apparent purpose of these communication patterns was to inform decision-making about further cancer treatment and not primarily for symptom management.

The outcome of 43 post-treatment follow-up consultations varied by location within the model of communication; yet, only one patient was prescribed symptomatic treatment. Patients were advised to resume cancer therapy only where clinical information was 'negative' (i.e. indicating disease recurrence) and had high certainty (Cells 2 and 4). One exception occurred where a patient with an elevated ovarian cancer tumour marker persistently complained of pain and its negative impact upon her (Cell 4). Otherwise, negative clinical information with low certainty was interpreted as either 'no change', or patients were advised to wait until they developed symptoms before resuming treatment or they were referred for tests which would yield high certainty clinical information.

Clinical information needed to be 'negative' in order for additional treatment to be recommended. However, this was not a requirement for patient information; in one case despite 'positive' patient information, further cancer treatment was advised (Cell 2).

Not surprisingly, no cancer treatment was offered where clinical information was 'positive' (Cells 1 and 3) especially where no symptoms were reported (Cell 1). However, reported patient 
problems in 14 consultations were not addressed except where a X-ray was advised to rule out cancer recurrence.

Certainty of clinical information appeared to influence the exchange of information within consultations. Where clinical information had high certainty, subjective patient experiences beyond 'How are you?' were neither elicited nor when volunteered, addressed in depth. Only where clinical information had low certainty did doctors ask patients about potential symptoms. However, these questions about symptoms were non-specific where clinical information was 'positive' (Cell 1).

There was evidence of 'negative' patient information in 28 consultations (Cells 3 and 4). Whilst cancer treatment was offered where 'negative' clinical information also existed (Cell 4), exploration of symptoms was, at best, limited. Only one patient, for whom further cancer treatment was no longer an option, was offered a prescription for pain. However, she was also advised to contact her general practitioner and Macmillan nurse, presumably to begin the transition to terminal care.

It is during post-treatment follow-up consultations that patients learn whether their cancer has recurred and further treatment is advisable. These decisions can be based on evidence gleaned from clinical investigations and observations as well as patients' reports. Thus, it is at this time that we could reasonably expect to see patients given an opportunity to discuss their problems and concerns and for symptoms to be identified. Our findings suggest this is not the case. Rather, it appears that oncologists organised information about patients according to a hierarchy whereby clinical information with high certainty was privileged over that with low certainty and little attention was given to patients' reports of symptoms (Anspach, 1987; Maynard, 1991; Mishler, 1984). However, in order for an individualised, holistic approach to patient care to be realised, patients' perspectives need to be sought (Stewart, 1984). Patients need to be encouraged to express their concerns and expectations, and describe their symptoms (Stewart et al., 1995) and doctors cannot simply rely on information derived from clinical investigations (Silverman and Bloor, 1990).

These oncologists appeared to be using routinised procedures when communicating with patients (Bloor, 1978b; McIntosh, 1977). When clinical information with high certainty was available, symptoms were not elicited, presumably because doctors felt they had necessary and sufficient information to make treatment decisions. It may be argued that they avoided asking 'unnecessary' questions so as not to become involved in lengthy and complex discussions about patients' illnesses and prognoses (McIntosh, 1978) during busy outpatient clinics. But this does not seem to be the case as $40 \%$ of these consultations lasted $10 \mathrm{~min}$ or longer. Despite what may seem ample opportunity for patients to raise issues, doctors appeared to present clinical information in such a way as to make it difficult for patients to pursue their concerns (McIntosh, 1978). Additionally, patients may have been dissuaded from volunteering information because they assumed it lacked relevance if doctors did not make enquiries. Alternatively, they may have avoided complaining for fear that symptoms may indicate disease recurrence (Lampic et al., 1995), a possibility they did not wish to confirm.

Our findings offer new insights into how patient information was communicated in specialist medical consultations. It would appear that these doctors defined their roles narrowly as providing specialist cancer services only and not symptom management per se. To achieve this, they only sought information that facilitated making treatment decisions and disregarded other information. Consequently, only those symptoms potentially palliated by cancer treatment were addressed.

In this clinic, there is the aim to have a nurse present during each consultation; however, when present, many nurses were engaged in administrative duties rather than acting in an advocacy role. Hence, there was little opportunity, if any, for them to discuss symptoms and other problems with patients during their time in clinic. Furthermore, doctors may not have recorded problems in patients' notes if they did not consider them to be relevant. If this is the case, other members of the team may also overlook those patients who are experiencing difficulties. Only those few patients receiving bone marrow transplants were routinely seen by a specialist nurse along with a doctor who could potentially help with symptoms not addressed by their doctors. Additionally, a nurse triage system had been initiated for patients receiving chemotherapy (patients not included in this sub-sample). Under this system, patients without abnormalities in their clinical parameters could receive their treatment without waiting to see a doctor. Despite the offer of a greatly shortened visit, these patients commonly, requested a consultation with a doctor. So, it would 
seem that these patients were for the most part, dependent upon their doctors for symptom recognition and management.

Therefore, in order for care to be more individualised and holistic, several measures might be instituted. It may be useful to clarify patients' expectations about symptoms. It may well be that they are seeking information about their relevance rather than their management. Doctors could ask questions in a variety of ways depending on the individual rather than in a routinised manner. Finally, oncologists may want to broaden their perspective to include symptom management, if that accords with patients' expectations, or explicitly refer them to their general practitioners if this is deemed more appropriate.

We have accounted for all patients using this model. We note that some cells contain few observations. This is hardly surprising with the small sample size. Further work may want to investigate this more thoroughly. There also may be a relationship between experience, gender or other characteristics of doctors and how patients' symptom information is managed. Our study has generated this hypothesis which was not subsequently investigated. Future research may wish to address this hypothesis; however, current data do not give any support to the suggestion that information exchange varies by doctor.

\section{ACKNOWLEDGEMENTS}

We thank all of the patients and their families who took part in this study as well as the doctors and nurses who allowed us to observe their interactions in the clinics. Thanks are also due to Prof. Moira Stewart for her helpful comments on an earlier draft. This work was undertaken by Margaret Rogers who was funded by a DOH research studentship and who received funding from the NHS Executive Eastern R\&D. Chris Todd was previously funded by the NHS Executive Eastern R\&D. The views expressed in this publication are those of the authors. No conflict of interest is declared. Ethical approval for this study was obtained from the Cambridge LREC.

\section{REFERENCES}

Anspach RR. 1987. Prognostic conflict in life-and-death decisions: The organization as an ecology of knowledge. J Health Soc Behav 28: 215-231.
Au E, Loprinzi CL, Dhodapkar M, Nelson T, Novotny P, Hammack J, O'Fallon J. 1994. Regular use of a verbal pain scale improves the understanding of oncology inpatient pain intensity. $J$ Clin Oncol 12(12): 2751-2755.

Blanchard CG, Labrecque MS, Ruckdeschel JC, Blanchard EB. 1988. Information and decision-making preferences of hospitalized adult cancer patients. Soc Sci Med 27(11): 1139-1145.

Blanchard CG, Labrecque MS, Ruckdeschel JC, Blanchard EB. 1990. Physician behaviors, patient perceptions, and patient characteristics as predictors of satisfaction of hospitalized adult cancer patients. Cancer 65(1): 186-192.

Blanchard CG, Ruckdeschel JC, Blanchard EB, Arena JG, Saunders NL, Malloy ED. 1983. Interactions between oncologists and patients during rounds. Ann Internal Med 99(5): 694-699.

Blanchard CG, Ruckdeschel JC, Fletcher BA, Blanchard EB. 1986. The impact of oncologists' behavior on patient satisfaction with morning rounds. Cancer 58(2): 387-393.

Bloor M. 1976. Bishop Berkeley and the adenotonsillectomy enigma: An exploration of variation in the social construction of medical disposals. Sociology 10(1): 43-61.

Bloor M. 1978a. On the analysis of observational data: A discussion of the worth and uses of inductive techniques and respondent validation. Sociology 12(3): 545-552.

Bloor M. 1978b. On the routinised nature of work in people-processing agencies: The case of adeno-tonsillectomy assessments in ENT outpatient clinics. In Relationships between Doctors and Patients, Davis A (ed.). Teakfield Limited: Farnborough, England; $29-47$.

Borgers R, Mullen P, Meertens R, et al. 1993. The information-seeking behaviour of cancer outpatients: A description of the situation. Patient Educ Counseling 22: 35-46.

Brown R, Butow PN, Boyer MJ, Tattersall MHN. 1999. Promoting patient participation in the cancer consultation: Evaluation of a prompt sheet and coaching in question asking. Br J Cancer 80: 242-248.

Brunelli C, Costantini M, Di Guilio P, et al. 1998. Quality of life evaluation: When do terminal cancer patients and health care providers agree? J Pain Symptom Manage 15(3): 151-158.

Butow PN, Dunn SM, Tattersall MHN, Jones QJ. 1995. Computer-based interaction analysis of the cancer consultation. Br J Cancer 71: 1115-1121.

Byrne PS, Long BEL. 1984. Doctors Talking to Patients. The Royal College of Practitioners: Exeter.

Chan A, Woodruff RK. 1997. Communicating with patients with advanced cancer. $J$ Palliative Care 13(3): 29-33.

Cleary JF, Carbone PP. 1997. Palliative medicine in the elderly. Cancer 80: 1335-1347. 
Cleeland CS, Gonin R, Hatfield AK, et al. 1994. Pain and its treatment in outpatients with metastatic cancer. N Engl J Med 330(9): 592-596.

Drew P, Heritage J. 1992. Analyzing talk at work: An introduction. In Talk at Work: Interaction in Institutional Settings, Drew P, Heritage J (eds). Cambridge University Press: Cambridge; 3-65.

Dunlop GM. 1989. A study of the relative frequency and importance of gastrointestinal symptoms and weakness in patients with far advanced cancer. Palliative Med 4: 37-43.

Fallowfield L. 1992. The ideal consultation. $\mathrm{Br} J$ Hospital Med 47(5): 364-367.

Ford S, Fallowfield L, Lewis S. 1994. Can oncologists detect distress in their out-patients and how satisfied are they with their performance during bad news consultations? Br J Cancer 70: 767-770.

Ford S, Fallowfield L, Lewis S. 1996. Doctor-patient interactions in oncology. Social Sci Med 42(11): 15111519.

Frankel RM. 1984. From sentence to sequence: Understanding the medical encounter through microinteractional analysis. Discourse Process 7: 135-170.

Glaser GB, Strauss A. 1965. Awareness of Dying. Aldine Publishing Company: Chicago.

Grande GE, Barclay SIG, Todd CJ. 1997. Difficulty of symptom control and general practitioners' knowledge of patients' symptoms. Palliative Med 11(5): 399-406.

Heaven CM. Maguire P. 1997. Disclosure of concerns by hospice patients and their identification by nurses. Palliative Med 11: 283-290.

Heritage J. 1997. Conversation analysis and institutional talk. Analysing data. In Qualitative Research: Theory, Method and Practice, Silverman D (ed.). Sage Publications: London; 161-182.

Higginson IJ. McCarthy M. 1993. Validity of the support team assessment schedule: Do staffs' ratings reflect those made by patients or their families? Palliative Med 7: 219-228.

Labrecque MS, Blanchard CG, Ruckdeschel JC, Blanchard EB. 1991. The impact of family presence on the physician-cancer patient interaction. Social Sci Med 11: $1253-1261$.

Lampic C, Nordin K, Sjoden P. 1995. Agreement between cancer patients and their physicians in the assessment of patient anxiety at follow-up visits. Psycho-Oncology 4(4): 301-310.

Larue F, Colleau SM, Brasseur L, Cleeland CS. 1995. Multicentre study of cancer pain and its treatment in France. $\mathrm{Br}$ Med J 310: 1034-1037.

Lutfey K, Maynard DW. 1998. Bad news in oncology: How physician and patient talk about death and dying without using those words. Soc Psychol Quarterly 61: 321-341.

Maguire P, Walsh S, Jeacock J, Kingston R. 1999. Physical and psychological needs of patients dying from colo-rectal cancer. Palliative Med 13: 45-50.
Malone M, Harris AL, Luscombe DK. 1993. Self assessment of health status and symptoms by cancer patients. Int $J$ Pharm Pract 2: 147-151.

Maynard DW. 1991. Interaction and asymmetry in clinical discourse. Am J Sociol 97(2): 448-495.

Maynard DW. 1992. On clinicians co-implicating recipients' perspective in the delivery of diagnostic news. In Talk at Work. Interactions in Institutional Settings, Drew P, Heritage J (eds). Cambridge University Press: Cambridge; 331-358.

McIntosh J. 1977. Communication and Awareness in a Cancer Ward. Croom Helm: London.

McIntosh J. 1978. The routine management of uncertainty in communication with cancer patients. In Relationships between Doctors and Patients, Davis A (ed.). Teakfield Limited: Farnborough, England; 106-131.

Mishler EG. 1984. The Discourse of Medicine: Dialectics of Medical Interviews. Ablex Publishing Corporation: Norwood NJ.

Newell S, Sanson-Fisher RW, Girgis A, Bonaventura A. 1998. How well do medical oncologists' perceptions reflect their patients' reported physical and psychosocial problems. Cancer 83(8): 1640-1651.

Northouse P. Northouse LLO. 1987. Communication and cancer: Issues confronting patients, health professionals and family members. J Psychosocial Oncol 5(3): $17-46$.

Passik SD, Dugan W, McDonald MV, Rosenfeld B, Theobald DE, Edgerton S. 1998. Oncologists' recognition of depression in their patients with cancer. $J$ Clin Oncol 16(4): 1594-1600.

Quint JC. 1965. Institutionalized practices of information control. Psychiatry 28: 119-132.

Roter DL, Hall JA. 1992. Doctors Talking with Patients, Patients Talking with Doctors: Improving Communication in Medical Visits. Aubern House: Westport, CT.

Sacks H. 1975. Everyone has to lie. In Sociocultural Dimensions of Language Use, Sanches M, Blount BG (eds). Academic Press: New York; 57-79.

Sher TG, Cella D, Leslie WT, Bonomi P, Taylor SG, Serafian B. 1997. Communication differences between physicians and their patients in an oncology setting. J Clin Psychol Med Settings 4(3): 281-293.

Siegel S, Castellan Jr. NJ. 1988. Nonparametric Statistics for the Behavioral Sciences (2nd edn). Magraw-Hill Book Company: New York.

Silverman D. 1993. Interpreting Qualitative Data: Methods for Analysing Talk, Text and Interaction. Sage Publications Ltd: London.

Silverman D, Bloor M. 1990. Patient-centered medicine: Some sociological observations on its constitution, penetration, and cultural assonance. In Advances in Medical Sociology: A Research Manual, vol. 1, Albrecht GL (ed.). JAI Press, Inc.: Greenwich, CT; 3-25. 
Siminoff LA, Fetting JH, Abeloff MD. 1989. Doctorpatient communication about breast cancer adjuvant therapy. J Clin Oncol 7(9): 1192-1200.

Slevin ML, Plant H, Lynch D, Drinkwater J, Gregory WM. 1988. Who should measure quality of life, the doctor or the patient? Br J Cancer 57: 109-112.

Stephens RJ, Hopwood P, Girling DJ, Machin D. 1997. Radomized trials with quality of life endpoints: Are doctors' ratings of patients' physical symptoms interchangeable with patients' self-ratings? Quality Life Res 6(3): 225-236.

Stewart M, Brown JB, Weston WW, McWhinney IR, McWilliam CL, Freeman TR. 1995. Patient-centered Medicine: Transforming the Clinical Method. Sage Publications: Thousand Oaks.

Stewart M, Roter D. 1989. Comunicating with Medical Patients. Sage Publications, Inc.: Newbury Park.

Stewart MA. 1984. What is a successful doctor-patient interview? A study of interactions and outcomes. Social Sci Med 19(2): 167-175.
Stewart MA. 1995. Effective physician-patient communication and health outcomes: A review. Can Med Assoc J 152(9): 1423-1433.

Stimson G, Webb B. 1975. Going to see the Doctor-The Consultation Process in General Practice. Routledge and Kegan Paul: London.

Street RL, Voigt B. 1997. Patient participation in deciding breast cancer treatment and subsequent quality of life. Med Decision Making 17: 298-306.

Sykes NP, Pearson SE, Chell S. 1992. Quality of care of the terminally ill: The carer's perspective. Palliative Med 6: 227-236.

Tuckett D, Boulton M, Olson C, Williams A. 1985. Meetings between Experts: An Approach to Sharing Ideas in Medical Consultations. Tavistock Publications: London.

Whelan TJ, Mohide EA, Willan AR, et al. 1997. The supportive care needs of newly diagnosed cancer patients attending a regional cancer center. Cancer 80(8): $1518-1524$. 